\title{
Development and validation of a nomogram for predicting the overall survival of patients with lung large cell neuroendocrine carcinoma
}

\author{
Junjie $\mathrm{Xi}^{1 \#}$, Mengnan Zhao ${ }^{1 \#}$, Yuansheng Zheng ${ }^{1 \#}$, Jiaqi Liang ${ }^{1}$, Zhengyang Hu ${ }^{1}$, Yiwei Huang ${ }^{1}$, \\ Yong Yang ${ }^{2}$, Cheng Zhan ${ }^{1}$, Wei Jiang ${ }^{1}$, Tao Lu ${ }^{1}$, Weigang Guo ${ }^{1}$, Qun Wang ${ }^{1}$ \\ ${ }^{1}$ Department of Thoracic Surgery, Zhongshan Hospital, Fudan University, Shanghai, China; ${ }^{2}$ Department of Thoracic Surgery, Suzhou Hospital \\ affiliated to Nanjing Medical University, Suzhou, China \\ Contributions: (I) Conception and design: T Lu, W Guo, J Xi; (II) Administrative support: W Jiang, Q Wang; (III) Provision of study materials or \\ patients: T Lu, J Xi, M Zhao, W Guo, J Liang; (IV) Collection and assembly of data: J Xi, Y Zheng, Z Hu, J Liang, Y Huang; (V) Data analysis and \\ interpretation: J Xi, M Zhao, Y Yang, C Zhan; (VI) Manuscript writing: All authors; (VII) Final approval of manuscript: All authors. \\ \#These authors contributed equally to this work. \\ Correspondence to: Tao Lu; Weigang Guo. Department of Thoracic Surgery, Zhongshan Hospital, Fudan University, 180 Fenglin Road, Shanghai \\ 200032, China. Email: lutao901118@163.com; guo.weigang@zs-hospital.sh.cn.
}

Background: Lung large cell neuroendocrine carcinoma (L-LCNEC) is a rare and rapidly progressing lung cancer. We aimed to formulate a nomogram model to predict the survival of L-LCNEC patients.

Methods: Clinical data of patients with L-LCNEC, lung large cell cancer (L-LCC) and small cell lung cancer (SCLC) were derived from the Surveillance, Epidemiology, and End Results (SEER) database. The characteristics and prognosis of L-LCNEC were investigated by comparing with that of L-LCC and SCLC, respectively. All L-LCNEC patients were randomly assigned into training group and validation group. A prognostic nomogram model was established for the overall survival (OS) in L-LCNEC patients. Furthermore, we enrolled 112 L-LCNEC patients from our department to validate the nomogram model.

Result: 3,076 L-LCNEC, 11,163 L-LCC, and 78,097 SCLC patients were collected and enrolled in our analyses. Compared with L-LCC and SCLC, differences were observed in L-LCNEC in age, sex, race, marital status, SEER registry, TNM stage, and treatment. Furthermore, higher proportions of L-LCNEC were located at the upper lobe and unilateral lung compared with SCLC. L-LCNEC has similar survival to L-LCC, but better than SCLC. We identified that the age, gender, T, N, and M classification, and treatment were the independent prognostic predictors. A nomogram model was formulated to predict the OS. Calibration curves were performed to show optimal coherence between predicted probability of survival and actual survival, with a concordance index of 0.775 . The external cohort included 112 patients and all of them underwent surgical treatment. The external validation demonstrated the reliability of this model.

Conclusions: The nomogram demonstrated its discrimination capability to predict the OS for L-LCNEC patients.

Keywords: Lung large cell neuroendocrine carcinoma (L-LCNEC); SEER database; nomogram; validation

Submitted Feb 01, 2020. Accepted for publication Jul 29, 2020.

doi: $10.21037 /$ tcr-20-780

View this article at: http://dx.doi.org/10.21037/tcr-20-780

\section{Introduction}

Lung large cell neuroendocrine carcinoma (L-LCNEC) is an uncommon histological type of lung cancer and presents an aggressive biological behavior, taking up approximately $3 \%$ of lung cancers (1).

According to the classification of 2004 World Health Organization (WHO), L-LCNEC was grouped into 
lung large cell carcinomas (L-LCC) (2). While in the recent WHO criteria, this subtype is categorized as a neuroendocrine tumor (3). L-LCNEC has been demonstrated as an aggressive tumor. Several reports suggested that the prognoses of L-LCNEC were poorer than that of L-LCC but similar to that of small cell lung cancer (SCLC) (4-6). Some researches revealed that L-LCNEC has a 5 -year survival rate of $15 \%$ to $57 \%(7,8)$. But some reports considered that SCLC and L-LCNEC were different tumors according to their morphology and phenotype $(9,10)$, and which therapeutic strategy to use for SCLC and for the treatment of L-LCNEC remains controversial. Based on the previous studies, whether L-LCNEC should be classified as SCLC or as L-LCC needs to be further evaluated. Therefore, we determined the characteristics and survival outcomes of L-LCNEC.

In addition, the prognostic characteristics of patients with LCNEC have been less extensively investigated. Nomogram models are widely used for prediction of survival in cancer patients, but there is still no report on a model for L-LCNEC. As a result, this study intended to develop a nomogram model based on the significant independent risk factors to predict the overall survival (OS) of patients with L-LCNEC. We present the following article in accordance with the STROBE reporting checklist (available at http://dx.doi.org/10.21037/tcr-20-780).

\section{Methods}

The data of L-LCNEC, L-LCC and SCLC cases were derived from the Surveillance, Epidemiology, and End Results (SEER) database. This database is publicly accessible. Thus, the research containing the data from SEER database was not required ethical approval. For the external validation cohort, the written informed consent was exempted by the Ethics Committee of Zhongshan Hospital, Fudan University for this retrospective study.

Patients with L-LCNEC (ICD-O-3 8013/3) from 2004 to 2015 and other L-LCC $(8012 / 3,8014 / 3)$ and SCLC $(8041 / 3,8043 / 3,8044 / 3,8045 / 3)$ from 2000 to 2015 were obtained and enrolled in this study. For the tumors, the labeled primary sites were limited to C34.1, C34.2, C34.3, C34.8, C34.9. The old version of tumor TNM stage was converted to the $8^{\text {th }}$ edition of the American Joint Committee on Cancer (AJCC) TNM stage, manually.

The data of patients and tumor characteristics, such as age, gender, race, year of diagnosis, marital status, origin recode NAACCR Hispanic Identification Algorithm
(NHIA), SEER registry, tumor primary site, laterality, tumor differentiation, T, N, M classification, stage, surgery recode, chemotherapy recode, radiation recode, survival time and survival outcomes, were obtained and enrolled in this study. Age was categorized subjectively as $\leq 60,60-70$, and $>70$ years.

The characteristics of patients with L-LCNEC, L-LCC, and SCLC, respectively, were compared using chi-square and Wilcoxon tests by IBM SPSS Statistics 24. In order to investigate the survival of three types of lung cancer, the propensity score matching (PSM) model was applied to control for variation in characteristics. Some important factors were matched between the L-LCNEC and L-LCC and between the L-LCNEC and SCLC groups: age, sex, race, TNM stage and treatment. For each patient with L-LCNEC, one case with L-LCC and SCLC was randomly chosen for pairing by PSM. The Kaplan-Meier survival curves were performed and compared using logrank tests in the three lung cancer groups. All L-LCENEC patients $(n=3,076)$ were randomized to training cohort $(n=2,461)$ and validation cohort $(n=615)$ by the ratio of 8:2. Univariate survival analyses and multivariate Cox model were performed to determine the independent predictors of the patients with L-LCNEC in the training group. The nomogram model was formulated based on the outcomes of the multivariate analyses. The concordance index (C-index) and the calibration curves were used to assess the prediction ability and compliance of the nomogram model.

Furthermore, internal validation using the validation cohort and external validation using the cohort $(n=112)$ provided by the database of the Department of Thoracic Surgery of Zhongshan Hospital were performed to examine the generalizability of the nomogram model.

Survival analysis, nomogram model establishment, and calibration curves were analyzed and plotted using $\mathrm{R}$ version 3.5.1. In this study, results of all statistical tests were considered significant if $\mathrm{P}$ value was at a level of less than 0.05 .

\section{Results}

\section{Patients characteristics}

The cases were selected as Figure 1. After selection, there were 3,076 patients with L-LCNEC, 11,163 patients with L-LCC, and 78,097 patients with SCLC involved in the current research (Table 1). No significant differences were observed in aspect of origin record NHIA, tumor primary 


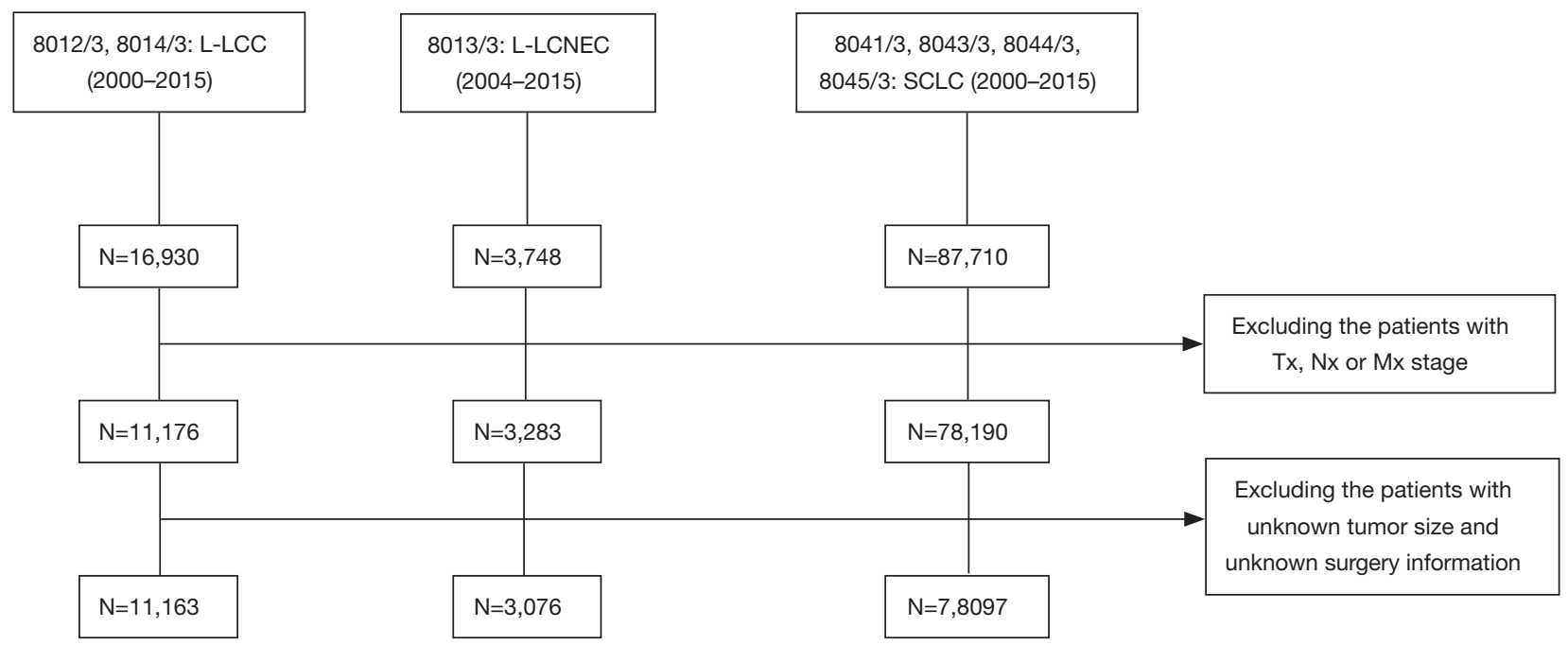

Figure 1 The flow chart of the patients selection.

site and laterality between L-LCNEC and L-LCC and also in origin record NHIA between L-LCNEC and SCLC, respectively. L-LCNEC patients were at younger ages than those with L-LCC or SCLC (all $\mathrm{P}<0.001$ ). Male patients occupied a larger proportion in L-LCNEC than SCLC $(\mathrm{P}<0.001)$, but smaller than L-LCC $(\mathrm{P}=0.001)$. White patients with LCNEC had a greater proportion than those with L-LCC $(\mathrm{P}=0.002)$, but had a smaller proportion than those with SCLC $(\mathrm{P}<0.001)$. More L-LCNEC patients were living without a spouse than L-LCC $(\mathrm{P}=0.002)$ and SCLC patients $(\mathrm{P}=0.048)$. Compared with SCLC, L-LCNEC and L-LCC were more likely to occur in the upper lobe and unilateral lung (all $\mathrm{P}<0.001$ ). More $\mathrm{L}-\mathrm{LCNEC}$ were at relatively early stage than $\mathrm{L}-\mathrm{LCC}(\mathrm{P}<0.001)$, while the vast majority of SCLC were at advanced stage $(\mathrm{P}<0.001)$. More L-LCNEC patients received active treatment than L-LCC and SCLC patients (all $\mathrm{P}<0.001$ ).

\section{Patient survival}

The median survival times of L-LCNEC, L-LCC, and SCLC patients were 12, 9, and 7 months, respectively. In general, before PSM, the 5-year OS rate was $20.2 \%$ of L-LCNEC, $15.8 \%$ of L-LCC, and 5.4\% of SCLC patients. L-LCNEC patients had better survival than L-LCC and SCLC patients, and the latter had the poorest prognosis (Figure $2 A ; \mathrm{P}<0.001$ ). After matching, survival of L-LCNEC patients was close to that of L-LCC, but better than that of SCLC patients (Figure $2 B ; \mathrm{P}<0.001$ ).

The L-LCNEC patients were randomly divided into two groups, and all the characteristics of the patients between the two groups were not significant (Table 2). For the patients with L-LCNEC in the training cohort, univariate analyses showed that the age, sex, SEER registry, tumor primary site, laterality, tumor grade, $\mathrm{T}$ classification, $\mathrm{N}$ classification, $\mathrm{M}$ classification, TNM stage, and treatment were the statistically significant predictors of OS (all $\mathrm{P}<0.05$ ). No significance was found in aspects of race, marital status and origin record NHIA (all $\mathrm{P} \geq 0.05$ ). Multivariate analyses identified age, sex, $\mathrm{T}$ classification, $\mathrm{N}$ classification, $\mathrm{M}$ classification, and treatment as the independent prognostic predictors for L-LCNEC $(\mathrm{P}<0.05$; Table 3).

\section{Nomogram model}

Based on the independent predictors in the training cohort, a nomogram model was formulated for prediction of the prognosis of individual L-LCNEC patient (Figure 3). We subjectively set the maximum score of the point scale to 100. According to the hazard level related to the prognosis, each risk factor was set to a specific score. The nomogram illustrated that the factor of treatment was the largest contributor to prognosis of L-LCNEC, followed by the factor of $\mathrm{M}$ classification, $\mathrm{N}$ classification, age, $\mathrm{T}$ classification and sex. After adding up the scores for all risk factor of each patients, we could easily calculate the survival possibility at any time point. The calibration curves presented a preferable coherence between the predicted survival probability and actual survival rate 
Table 1 The characteristics of L-LCNEC, L-LCC and SCLC patients before and after matching

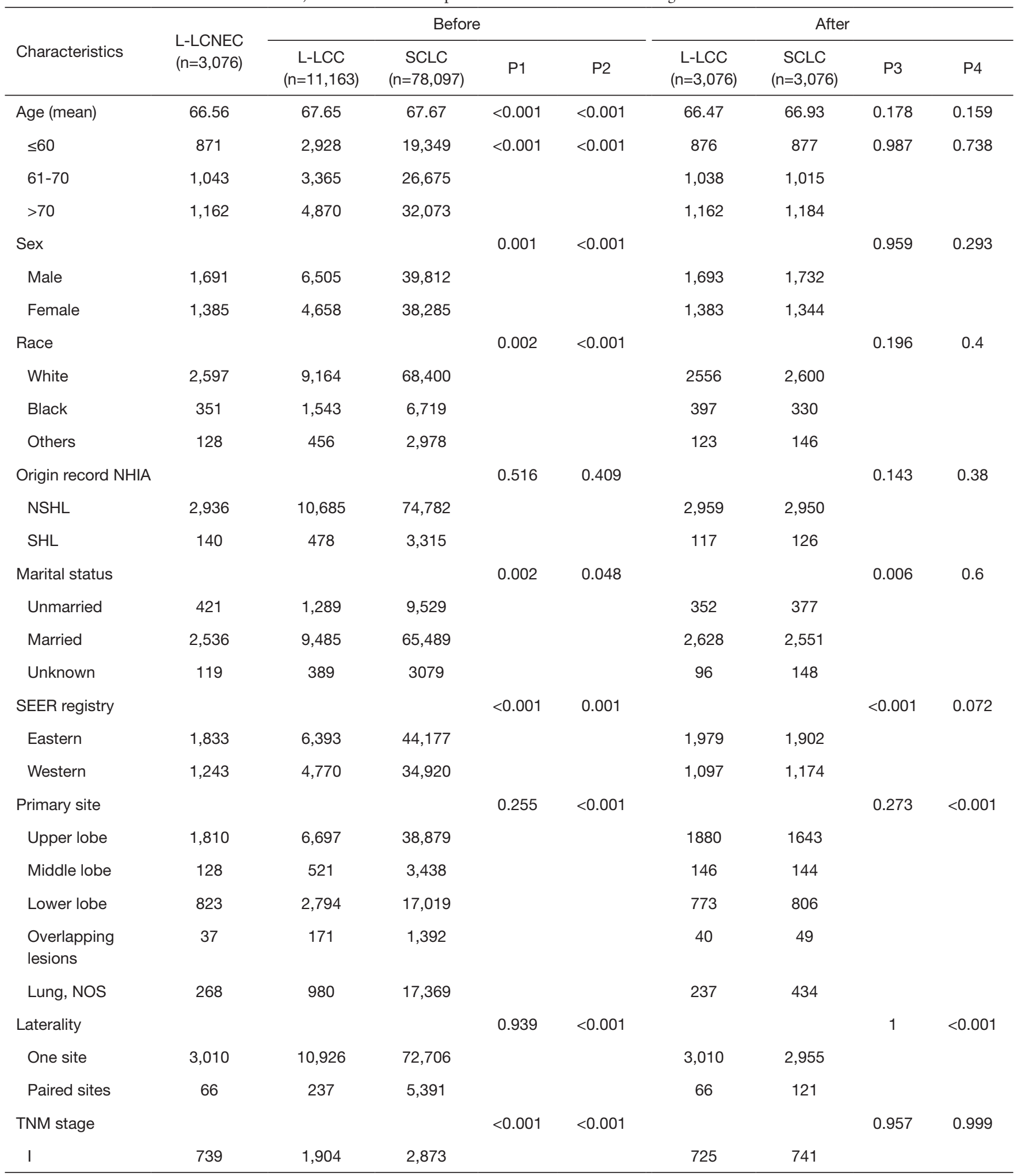

Table 1 (continued) 
Table 1 (continued)

\begin{tabular}{|c|c|c|c|c|c|c|c|c|c|}
\hline Characteristics & $\begin{array}{l}\text { L-LCNEC } \\
(n=3,076)\end{array}$ & \multicolumn{4}{|c|}{ Before } & \multicolumn{4}{|c|}{ After } \\
\hline III & 687 & 3,766 & 21,652 & & & 690 & 689 & & \\
\hline No treatment & 446 & 2,363 & 18,891 & & & 445 & 540 & & \\
\hline Surgery alone & 760 & 2,261 & 763 & & & 761 & 697 & & \\
\hline RT alone & 258 & 1,643 & 4,734 & & & 258 & 278 & & \\
\hline $\mathrm{RT}+\mathrm{CT}$ & 658 & 2,519 & 28,814 & & & 659 & 658 & & \\
\hline $\begin{array}{l}\text { Surgery + CT + } \\
\text { RT }\end{array}$ & 166 & 458 & 833 & & & 179 & 178 & & \\
\hline
\end{tabular}

(Figure $4 A, B, C$ ). The $\mathrm{C}$-index of the nomogram model was 0.775 (95\% CI: 0.786-0.764), indicating a strong predictive value of this model. We performed an internal validation of the nomogram model by using the validation cohort. The calibration curves showed a good coherence (Figure 4D,E,F). The C-index was 0.785 (95\% CI: 0.765-0.805).

Furthermore, we also validated the nomogram model by using the cohort in our department $(n=112)$. There were 73 male patients and 39 female patients. All of them received the surgical treatment. Among them, 43 patients received adjuvant chemotherapy. The mean overall survival time was 37.2 months. The factors of age, sex, $\mathrm{T}$ stage, $\mathrm{N}$ stage and $M$ stage were included to validate the nomogram model (Table 4). The calibration curves also showed an acceptable coherence (Figure $4 G, H, I$ ). The C-index was also great for the nomogram prediction $(0.742,95 \%$ CI: 0.679-0.806).

Based on the total risk scores, we subjectively classified all primary cohort as five subgroups $(\leq 50,50-100,100-150$, $150-200$, and $>200$ ), and the survival differences of these groups were evaluated (Table 5). Each group represented a distinct prognosis. The higher the score, the worse the prognosis (Figure 5). Furthermore, we analyzed the risk subgroup stratification within each TNM stage and the results exhibited significant distinctions of OS (all $\mathrm{P}<0.001$; Figure 6).

\section{Discussion}

In the present study, we compared the characteristics and survival of L-LCNEC with that of L-LCC and SCLC. There were some differences between L-LCNEC and L-LCC and between L-CNEC and SCLC regarding age, gender, race, tumor differentiation, TNM stage, RNE, surgery, chemotherapy, and radiotherapy rates. We showed that the survival of L-LCNEC was close to that of L-LCC rather than SCLC. Furthermore, we established a nomogram model to predict the prognosis of the patients with L-LCNEC. Lung neuroendocrine tumors are regarded as a unique classification of lung cancer, which can be further classified into four subtypes of SCLC, LCNEC, typical carcinoid, and atypical carcinoid according to the morphology (3). Among them, SCLC and L-LCNEC are considered to be highgrade neuroendocrine tumors. Although L-LCNEC and SCLC share some similar biological characteristics, such as expression of neuroendocrine markers (11) and genetic alterations (12), there are still some differences between the two subtypes of lung cancers in genomic profiles (13) 

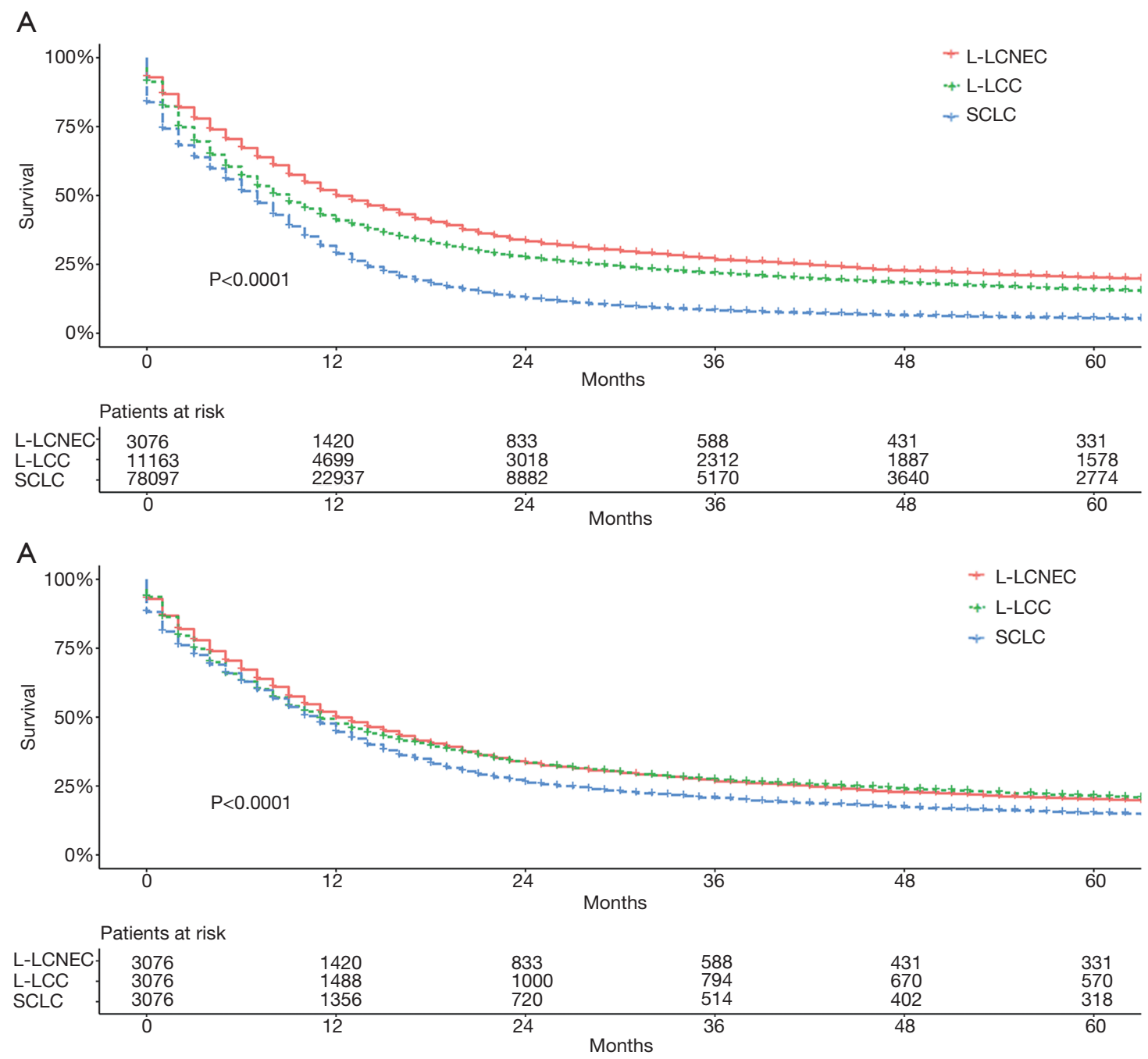

Figure 2 The overall survival of patients with L-LCNEC, L-LCC and SCLC were estimated by Kaplan-Meier analyses and log-rank tests. (A) Before matching; (B) After matching.

and the expression of other makers such as E-cadherin and CK7 (9). Therefore, whether L-LCNEC should be categorized as classic L-LCC or SCLC remains controversial. Varlotto et al. (14) compared the OS and cause-specific survival (CSS) of L-LCNEC with L-LCC and SCLC, revealing that the survival of L-LCNEC was close to other L-LCC and superior to SCLC. Moreover, they found L-LCNEC was more similar to L-LCC than to SCLC in aspects of the clinical, histopathological, and biological features. Similarly, Sun and associates (15) showed that L-LCNEC had a poor survival and observed no significant difference compared with classic L-LCC. In a small cohort study, the patients with L-LCNEC were more likely to receive open thoracotomy than those with L-LLC.
Postoperative adjuvant treatment was not associated to the histologic subtypes (15). Isaka et al. (16) suggested that better prognoses were observed in L-LCNEC patients than SCLC patients with small-size tumors (maximum diameter of $3.0 \mathrm{~cm}$ ), but they did not investigate the larger size tumors. However, studies reported that L-LCNEC had poorer prognosis than L-LCC but similar to SCLC, even in early stages (4-6,17-20).

This study identified the age, gender, T, N, M classification, and treatment were independent prognostic predictors for L-LCNEC. Male patients had poor prognosis probably because of a preponderance of male smokers. We showed that the treatment strategy was an independent predictor for the prognoses of L-LCNEC patients. Patients 
Table 2 The characteristics of the patients in the training group and validation group

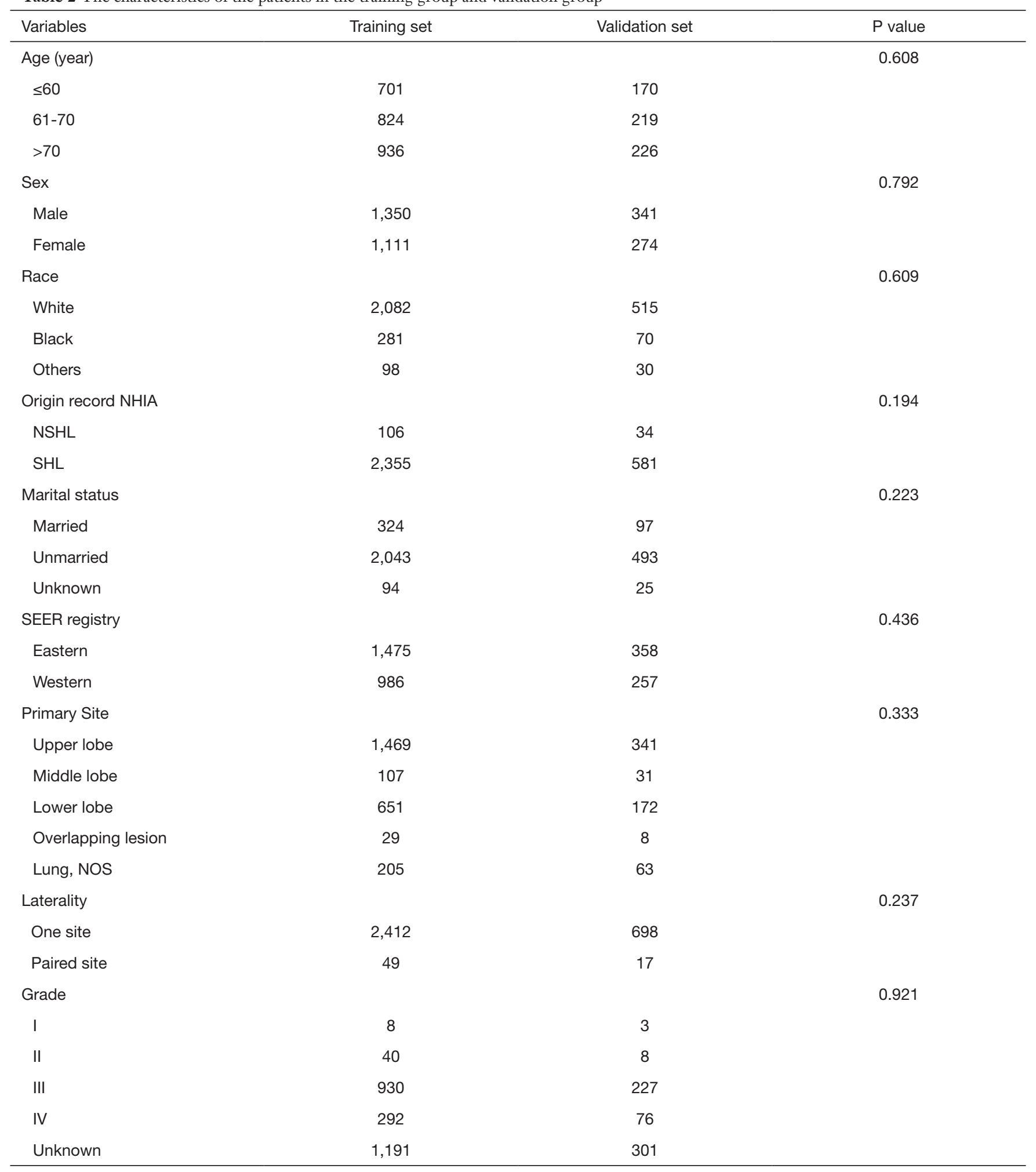

Table 2 (continued) 
Table 2 (continued)

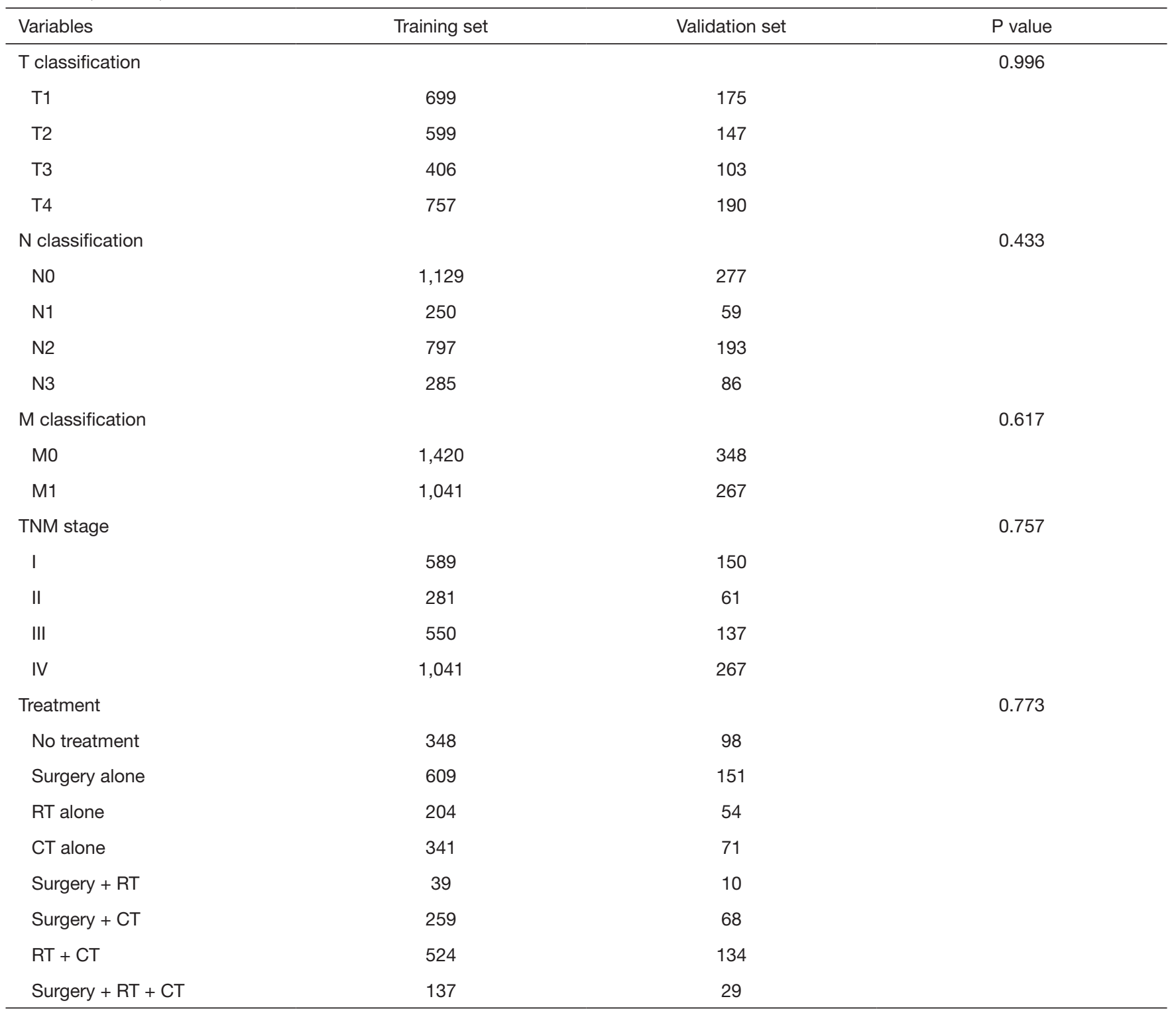

Table 3 Univariate and multivariate analyses of overall survival for L-LCNEC patients

\begin{tabular}{|c|c|c|c|c|c|c|}
\hline Variables & \multicolumn{3}{|c|}{ Univariate analysis } & \multicolumn{3}{|c|}{ Multivariate analysis } \\
\hline Age (year) & & & $<0.001$ & & & $<0.001$ \\
\hline$\leq 60$ & Reference & & & Reference & Reference & \\
\hline $61-70$ & 1.156 & $1.037-1.288$ & 0.009 & 1.22 & $1.078-1.381$ & 0.002 \\
\hline \multicolumn{7}{|l|}{ Sex } \\
\hline Male & Reference & & & Reference & Reference & \\
\hline
\end{tabular}

Table 3 (continued) 
Table 3 (continued)

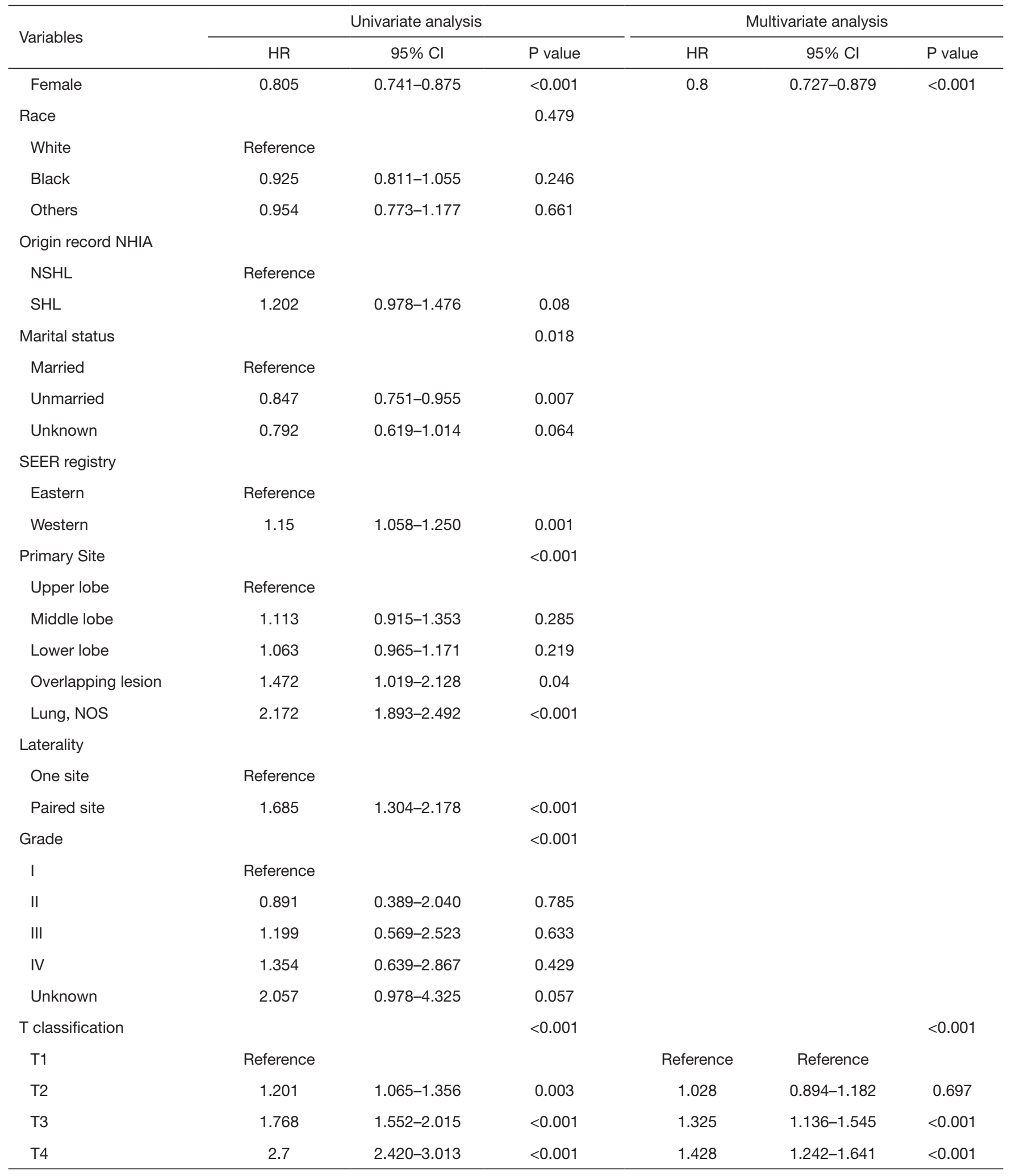

Table 3 (continued) 
Table 3 (continued)

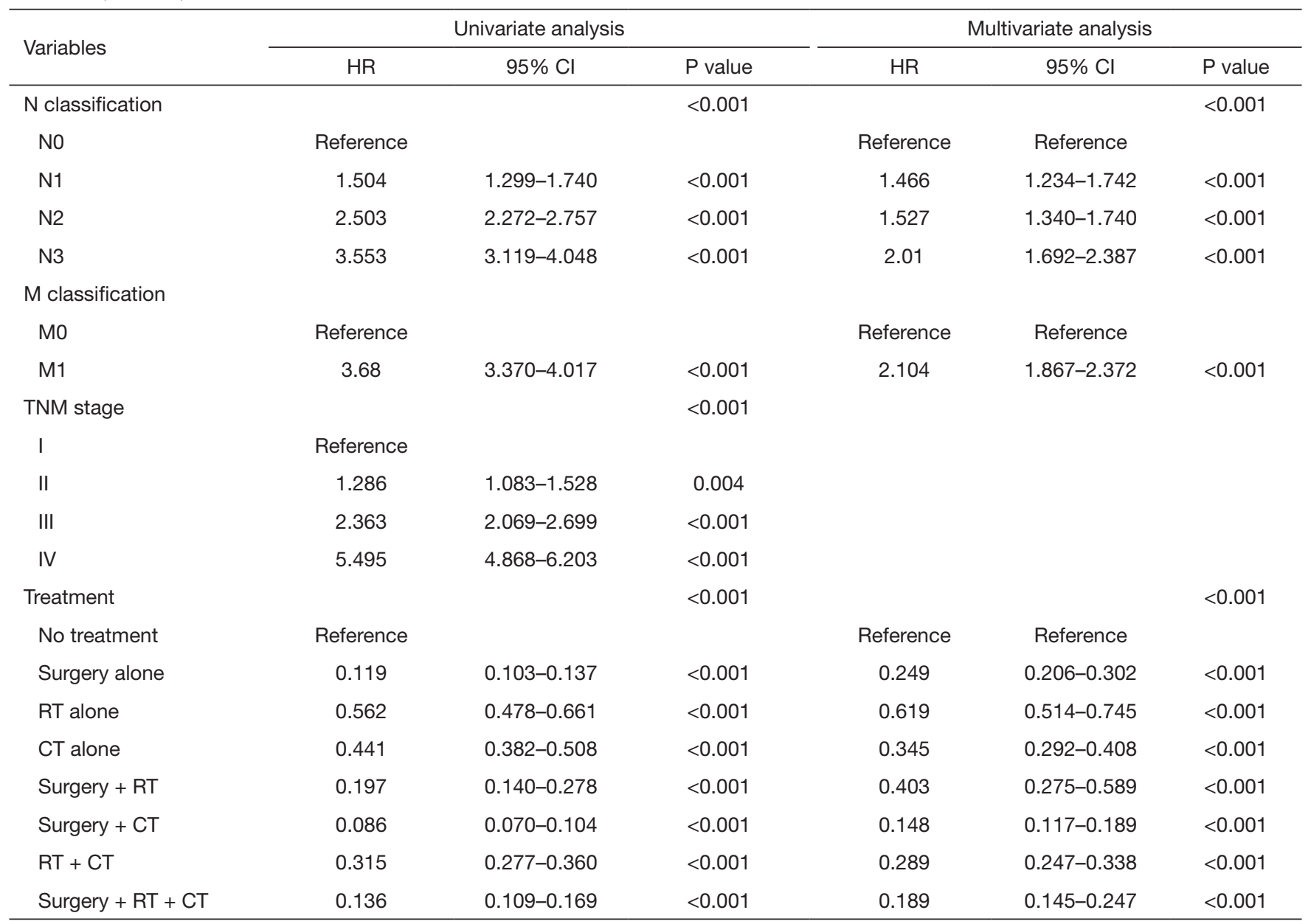

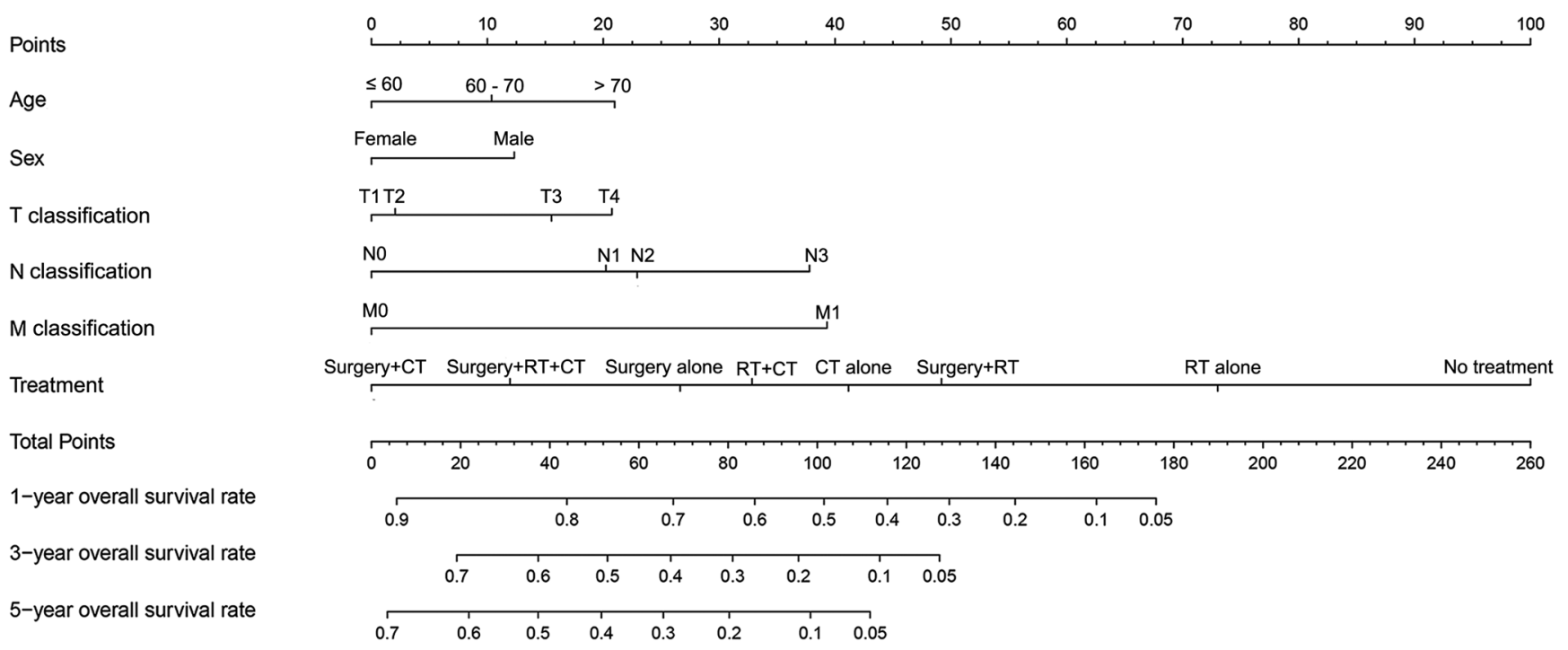

Figure 3 Nomogram to predict 1-, 3-, and 5-year overall survival of patients with L-LCNEC. 


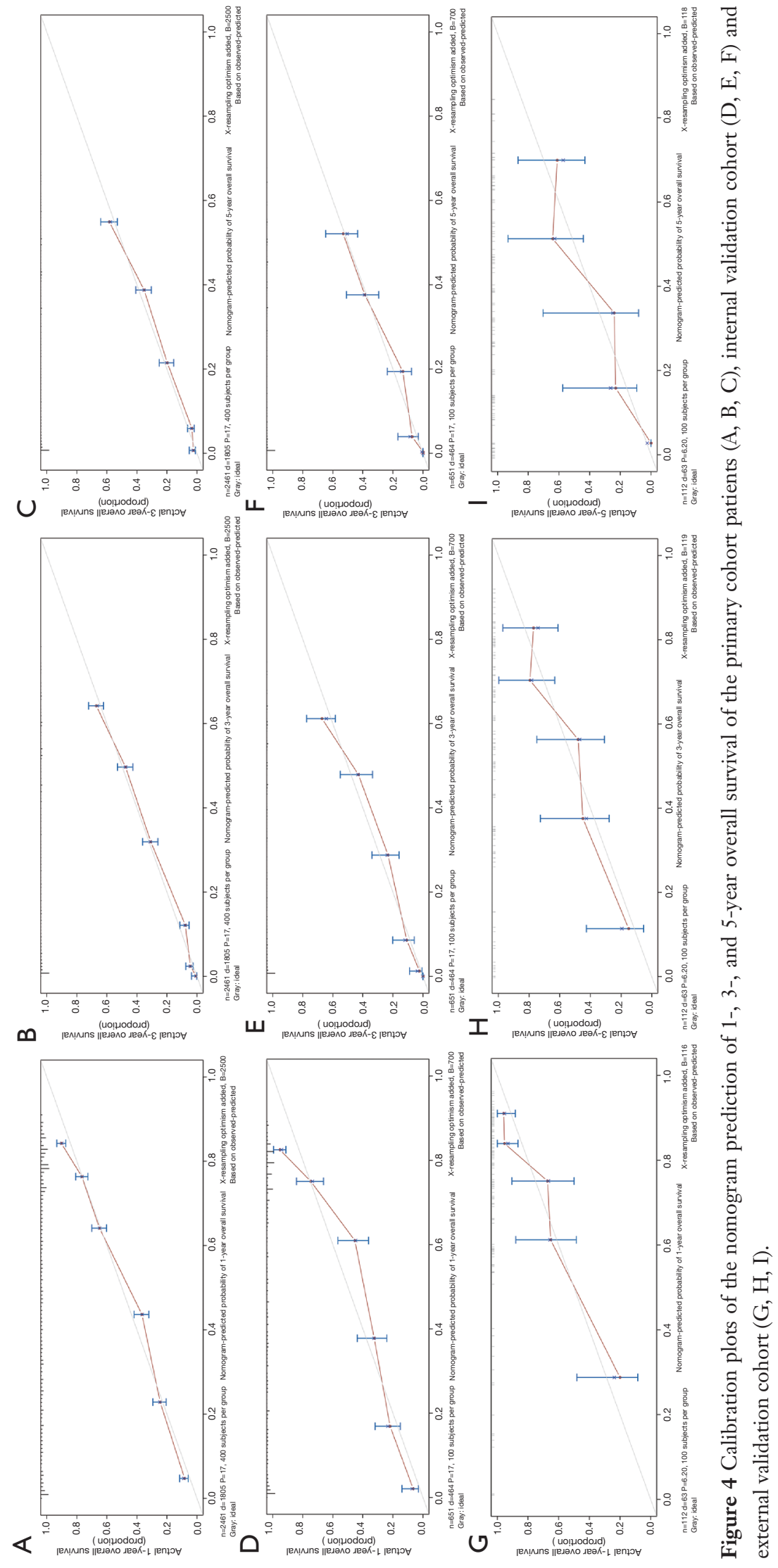


Table 4 The characteristics of the patients with L-LCNEC in external validation cohort

\begin{tabular}{|c|c|}
\hline Characteristics & No. $(n=112)$ \\
\hline \multicolumn{2}{|l|}{ Age (year) } \\
\hline$\leq 60$ & 39 \\
\hline $61-70$ & 35 \\
\hline$>70$ & 38 \\
\hline \multicolumn{2}{|l|}{ Sex } \\
\hline Male & 73 \\
\hline Female & 39 \\
\hline \multicolumn{2}{|l|}{ T classification } \\
\hline $\mathrm{T} 1$ & 49 \\
\hline $\mathrm{T} 2$ & 37 \\
\hline T3 & 17 \\
\hline $\mathrm{T} 4$ & 9 \\
\hline \multicolumn{2}{|l|}{$\mathrm{N}$ classification } \\
\hline NO & 80 \\
\hline N1 & 15 \\
\hline N2 & 17 \\
\hline N3 & 0 \\
\hline \multicolumn{2}{|l|}{ M classification } \\
\hline MO & 108 \\
\hline M1 & 4 \\
\hline \multicolumn{2}{|l|}{ TNM stage } \\
\hline I & 38 \\
\hline II & 44 \\
\hline III & 26 \\
\hline IV & 4 \\
\hline \multicolumn{2}{|l|}{ Treatment } \\
\hline Surgery alone & 69 \\
\hline Surgery + CT & 43 \\
\hline
\end{tabular}

who received no treatment had the highest scores in the nomogram model, indicating that these patients had poorest survival. At present, surgical treatment remained the main curative option for L-LCNEC, but surgery alone may be not enough, even in the early stages (21). L-LCNEC patients could benefit from adjuvant chemotherapy. It was reported that surgery plus chemotherapy showed survival benefit over surgery alone for L-LCNEC patients (21-23). However, the role of radiotherapy in L-LCNEC remained unclear because of the lack of prospective studies (24-26). For the L-LCNEC patients treated with nonoperative treatment, survival were dismal $(23,27)$. Derks et al. (28) showed that patients with metastatic LCNEC receiving platinum/gemcitabine have a better OS than those receiving a longer overall survival than those receiving SCLCoriented chemotherapy. The response rate to platinumbased neoadjuvant chemotherapy was high in LCNEC (29). However, the chemotherapy efficacy was poor in clinic. Tyrosine kinase inhibitors have clinically significant effect in NSCLC harboring EGFR mutations. But EGFR mutations were rarely found in LCNEC. Aroldi et al. (30) report a L-LCNEC patient with EGFR mutations was response well to gefitinib. In the present study, surgery combined with adjuvant chemotherapy achieved better results than other treatment approaches in terms of survival for patients with L-LCNEC.

This study developed a nomogram model to predict the survival probability of individual L-LCNEC patients. This is the first nomogram model to our knowledge reported for the L-LCNEC patients based on a large clinical database, with long-term follow-up. In our nomogram model, the characteristics of the patients with L-LCNEC, including advanced age, male, higher T, N, M classification and nontreatment, acquired higher points indicating less probability of OS. Calibration curves presented preferable coherence between the predicted survival probability and actual

Table 5 The 1-, 3-, 5-year survival rate of stratified risk groups

\begin{tabular}{lccccc}
\hline $\begin{array}{l}\text { Total prognostic } \\
\text { scores }\end{array}$ & No. & MST (month) & $\begin{array}{c}\text { 1-year overall survival } \\
\text { rate (\%) }\end{array}$ & $\begin{array}{c}\text { 3-year overall survival } \\
\text { rate }(\%)\end{array}$ & $\begin{array}{c}5 \text {-year overall survival } \\
\text { rate }(\%)\end{array}$ \\
\hline$\leq 50$ & 616 & 61 & 86.2 & 60.2 & 50.6 \\
$50-100$ & 689 & 20 & 66.6 & 34.5 & 23.2 \\
$100-150$ & 685 & 8 & 30.3 & 5.7 & 2.7 \\
$150-200$ & 367 & 2 & 10.8 & 1.3 & 0.0 \\
$>200$ & 104 & 1 & 3.1 & 0 & 0 \\
\hline
\end{tabular}

MST, median survival time. 


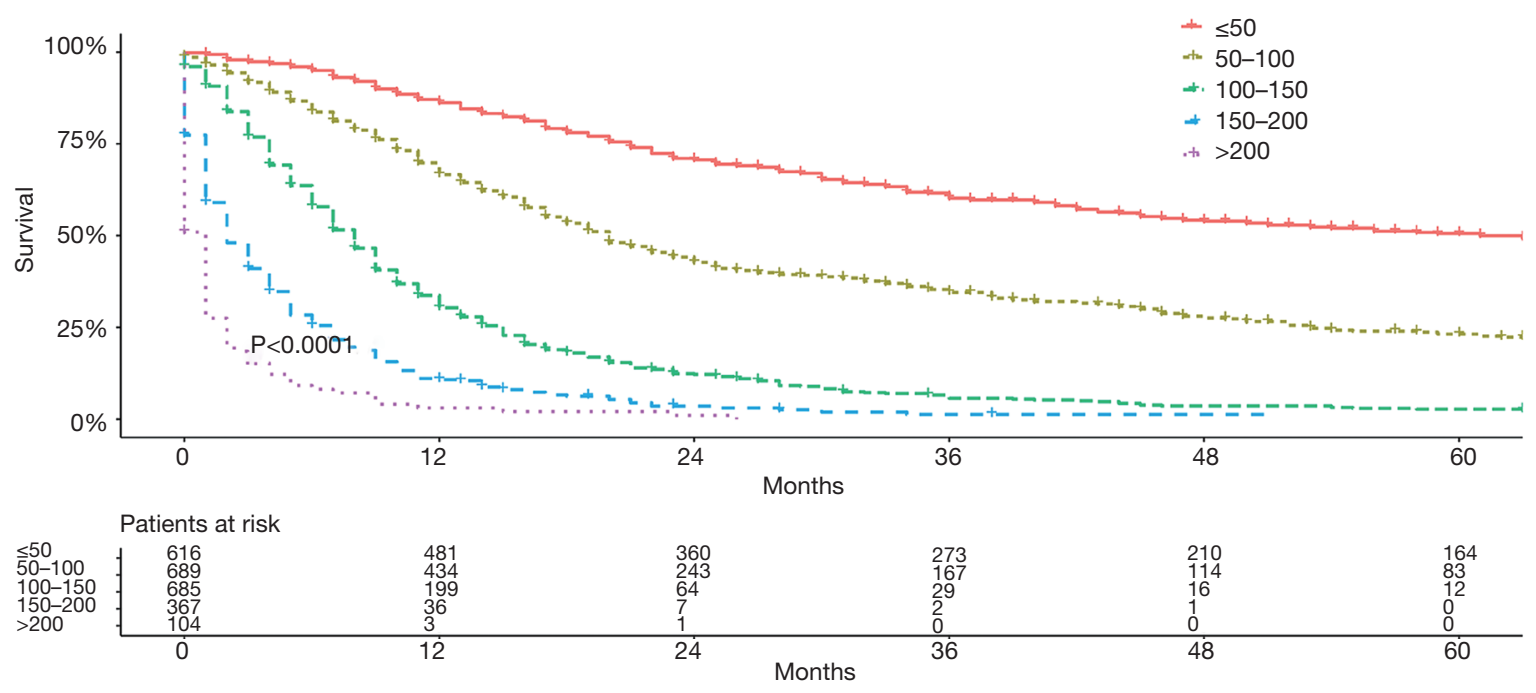

Figure 5 The overall survival of patients with L-LCNEC were analyzed by dividing five subgroups according to the prognostic scores.
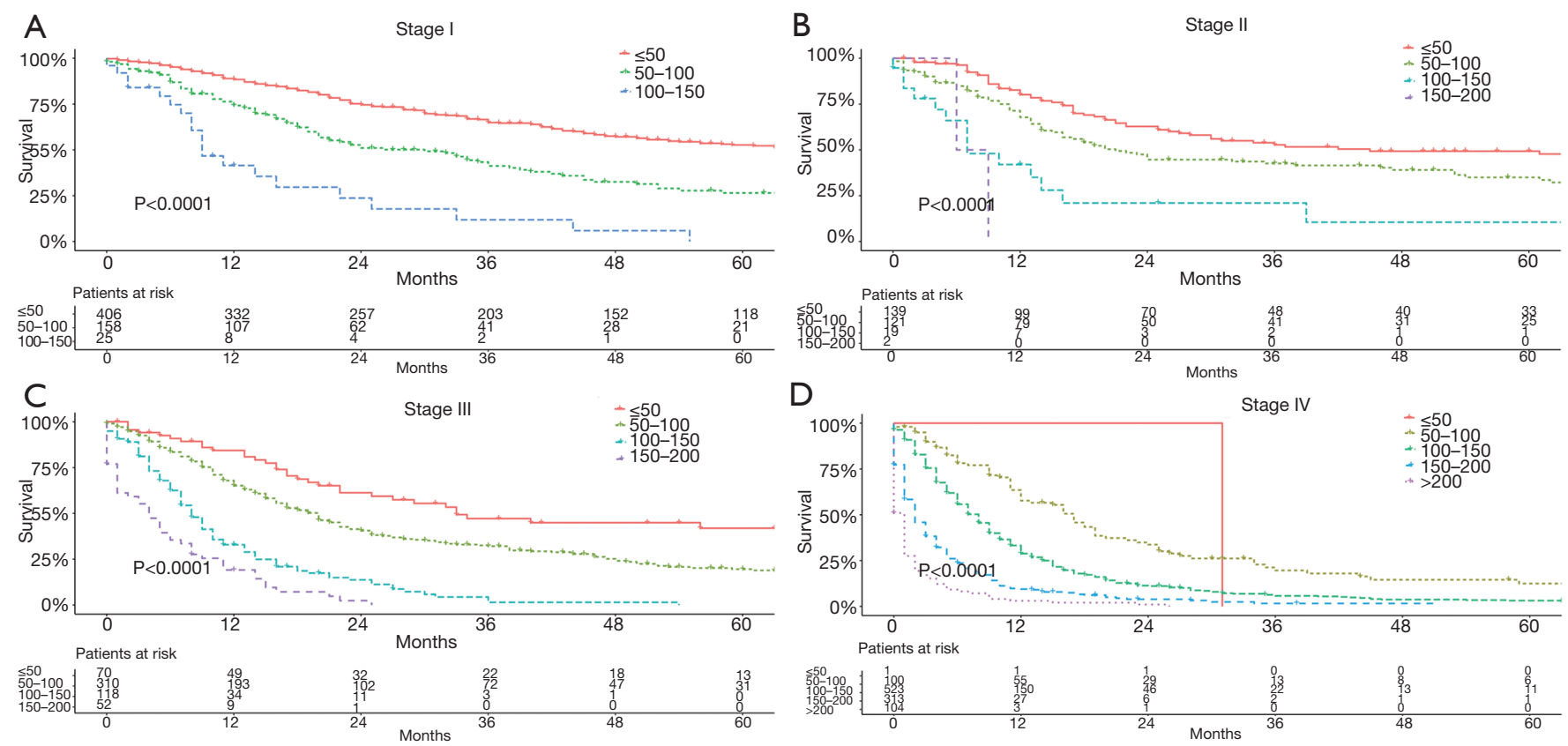

Figure 6 Risk groups stratification within each TNM stage were analyzed by Kaplan-Meier analyses and log-rank tests.

survival rate, indicating the model had satisfied feasibility and reliability. In this nomogram model, the $\mathrm{C}$-index was 0.775 , exhibiting a sufficient level of discrimination. Moreover, we performed the internal and external validation of the nomogram model and demonstrated its the reliability. Hence, we believe that both clinicians and patients could predict an individual survival according to this model.

The most important limitation of this study derived from the failure to incorporate more potential prognostic factors. The clinical data were obtained from the SEER database, and many parameters were not recorded or incomplete. Therefore, some important characteristics, such as vascular invasion and peri-neural invasion, and some important molecular factors, such as epidermal growth factor receptor mutations, were not included in the analyses. Further efforts incorporating more factors should be made to improve this 
nomogram model.

\section{Conclusions}

L-LCNEC had distinct clinical characteristics from L-LCC and SCLC. The L-LCNEC patients have similar survival with L-LCC patients, but significantly better than SCLC patients. The nomogram model we established demonstrated its prediction capability and could help clinicians more precisely estimate the survival rate of individual patient with L-LCNEC.

\section{Acknowledgments}

We thank the native English-speaking experts from International Science Editing for language editing.

Funding: This work was supported by Key r\&d and transformation projects in Tibet, China (XZ201901GB-01).

\section{Footnote}

Reporting Checklist: The authors have completed the STROBE reporting checklist. Available at http://dx.doi. org/10.21037/tcr-20-780

Conflicts of Interest: All authors have completed the ICMJE uniform disclosure form (available at http://dx.doi. org/10.21037/tcr-20-780). The authors have no conflicts of interest to declare.

Ethical Statement: The authors are accountable for all aspects of the work in ensuring that questions related to the accuracy or integrity of any part of the work are appropriately investigated and resolved. The research containing the data from SEER database was not required ethical approval. For the external validation cohort, the written informed consent was exempted by the Ethics Committee of Zhongshan Hospital, Fudan University for this retrospective study.

Open Access Statement: This is an Open Access article distributed in accordance with the Creative Commons Attribution-NonCommercial-NoDerivs 4.0 International License (CC BY-NC-ND 4.0), which permits the noncommercial replication and distribution of the article with the strict proviso that no changes or edits are made and the original work is properly cited (including links to both the formal publication through the relevant DOI and the license). See: https://creativecommons.org/licenses/by-nc-nd/4.0/.

\section{References}

1. Naidoo J, Santos-Zabala ML, Iyriboz T, et al. Large Cell Neuroendocrine Carcinoma of the Lung: ClinicoPathologic Features, Treatment, and Outcomes. Clin Lung Cancer 2016;17:e121-9.

2. Travis WD BE, Muller-Hermelink HK, Harris C. Tumours of the lung, pleura, thymus and heart. In: Pathology and Genetics. World Health Organization Classification of Tumours. Lyon: IARC Press, 2004.

3. Travis WD BE, Burke AP, Marx A, Nicholson A, eds. WHO Classification of Tumours of the Lung, Pleura, Thymus and Heart. Lyon, IARC Press, 2015.

4. Asamura H, Kameya T, Matsuno Y, et al. Neuroendocrine neoplasms of the lung: a prognostic spectrum. J Clin Oncol 2006;24:70-6.

5. Iyoda A, Hiroshima K, Baba M, et al. Pulmonary large cell carcinomas with neuroendocrine features are high-grade neuroendocrine tumors. Ann Thorac Surg 2002;73:1049-54.

6. Travis WD, Linnoila RI, Tsokos MG, et al. Neuroendocrine tumors of the lung with proposed criteria for large-cell neuroendocrine carcinoma. An ultrastructural, immunohistochemical, and flow cytometric study of 35 cases. Am J Surg Pathol 1991;15:529-53.

7. Filosso PL, Ruffini E, Di Gangi S, et al. Prognostic factors in neuroendocrine tumours of the lung: a single-centre experience. Eur J Cardiothorac Surg 2014;45:521-6; discussion 526.

8. Iyoda A, Hiroshima K, Nakatani Y, et al. Pulmonary large cell neuroendocrine carcinoma: its place in the spectrum of pulmonary carcinoma. Ann Thorac Surg 2007;84:702-7.

9. Nitadori J, Ishii G, Tsuta K, et al. Immunohistochemical differential diagnosis between large cell neuroendocrine carcinoma and small cell carcinoma by tissue microarray analysis with a large antibody panel. Am J Clin Pathol 2006;125:682-92.

10. Hiroshima K, Iyoda A, Shida T, et al. Distinction of pulmonary large cell neuroendocrine carcinoma from small cell lung carcinoma: a morphological, immunohistochemical, and molecular analysis. Mod Pathol 2006; 19:1358-68.

11. Takei H, Asamura H, Maeshima A, et al. Large cell neuroendocrine carcinoma of the lung: a clinicopathologic study of eighty-seven cases. J Thorac Cardiovasc Surg 
2002;124:285-92.

12. Hiroshima K, Iyoda A, Shibuya K, et al. Genetic alterations in early-stage pulmonary large cell neuroendocrine carcinoma. Cancer 2004;100:1190-8.

13. Ullmann R, Petzmann S, Sharma A, et al. Chromosomal aberrations in a series of large-cell neuroendocrine carcinomas: unexpected divergence from small-cell carcinoma of the lung. Hum Pathol 2001;32:1059-63.

14. Varlotto JM, Medford-Davis LN, Recht A, et al. Should large cell neuroendocrine lung carcinoma be classified and treated as a small cell lung cancer or with other large cell carcinomas? J Thorac Oncol 2011;6:1050-8.

15. Sun YH, Lin SW, Hsieh CC, et al. Treatment outcomes of patients with different subtypes of large cell carcinoma of the lung. Ann Thorac Surg 2014;98:1013-9.

16. Isaka $M$, Nakagawa $K$, Ohde $Y$, et al. A clinicopathological study of peripheral, small-sized high-grade neuroendocrine tumours of the lung: differences between small-cell lung carcinoma and large-cell neuroendocrine carcinoma. Eur J Cardiothorac Surg 2012;41:841-6.

17. Naranjo Gomez JM, Gomez Roman JJ. Behaviour and survival of high-grade neuroendocrine carcinomas of the lung. Respir Med 2010;104:1929-36.

18. Iyoda A, Hiroshima K, Toyozaki T, et al. Clinical characterization of pulmonary large cell neuroendocrine carcinoma and large cell carcinoma with neuroendocrine morphology. Cancer 2001;91:1992-2000.

19. Battafarano RJ, Fernandez FG, Ritter J, et al. Large cell neuroendocrine carcinoma: an aggressive form of non-small cell lung cancer. J Thorac Cardiovasc Surg 2005;130:166-72.

20. Paci M, Cavazza A, Annessi V, et al. Large cell neuroendocrine carcinoma of the lung: a 10-year clinicopathologic retrospective study. Ann Thorac Surg 2004;77:1163-7.

21. Saji H, Tsuboi M, Matsubayashi J, et al. Clinical response of large cell neuroendocrine carcinoma of the lung to perioperative adjuvant chemotherapy. Anticancer Drugs

Cite this article as: Xi J, Zhao M, Zheng Y, Liang J, Hu Z, Huang Y, Yang Y, Zhan C, Jiang W, Lu T, Guo W, Wang Q. Development and validation of a nomogram for predicting the overall survival of patients with lung large cell neuroendocrine carcinoma. Transl Cancer Res 2020;9(8):4943-4957. doi: $10.21037 /$ tcr-20-780
2010;21:89-93.

22. Kujtan L, Muthukumar V, Kennedy KF, et al. The Role of Systemic Therapy in the Management of Stage I Large Cell Neuroendocrine Carcinoma of the Lung. J Thorac Oncol 2018;13:707-14.

23. Abedallaa N, Tremblay L, Baey C, et al. Effect of chemotherapy in patients with resected small-cell or large-cell neuroendocrine carcinoma. J Thorac Oncol 2012;7:1179-83.

24. Rieber J, Schmitt J, Warth A, et al. Outcome and prognostic factors of multimodal therapy for pulmonary large-cell neuroendocrine carcinomas. Eur J Med Res 2015;20:64.

25. Fasano M, Della Corte CM, Papaccio F, et al. Pulmonary Large-Cell Neuroendocrine Carcinoma: From Epidemiology to Therapy. J Thorac Oncol 2015;10:1133-41.

26. Metro G, Ricciuti B, Chiari R, et al. Survival outcomes and incidence of brain recurrence in high-grade neuroendocrine carcinomas of the lung: Implications for clinical practice. Lung Cancer 2016;95:82-7.

27. Iyoda A, Hiroshima K, Moriya Y, et al. Postoperative recurrence and the role of adjuvant chemotherapy in patients with pulmonary large-cell neuroendocrine carcinoma. J Thorac Cardiovasc Surg 2009;138:446-53.

28. Derks JL, van Suylen RJ, Thunnissen E, et al. Chemotherapy for pulmonary large cell neuroendocrine carcinomas: does the regimen matter? Eur Respir J 2017;49:1601838.

29. Sarkaria IS, Iyoda A, Roh MS, et al. Neoadjuvant and adjuvant chemotherapy in resected pulmonary large cell neuroendocrine carcinomas: a single institution experience. Ann Thorac Surg 2011;92:1180-6; discussion 1186-7.

30. Aroldi F, Bertocchi P, Meriggi F, et al. Tyrosine Kinase Inhibitors in EGFR-Mutated Large-Cell Neuroendocrine Carcinoma of the Lung? A Case Report. Case Rep Oncol 2014;7:478-83. 